\title{
Conceptual Design of a Fish Oil Extracting Machine
}

\author{
Tanko Bako*, John Okanagba Awulu, Anebi Joseph Garba \\ Department of Agricultural and Environmental Engineering, University of Agriculture, Makurdi, Nigeria
}

\author{
Email address: \\ engbako@gmail.com (T. Bako) \\ *Corresponding author
}

\section{To cite this article:}

Tanko Bako, John Okanagba Awulu, Anebi Joseph Garba. Conceptual Design of a Fish Oil Extracting Machine. American Journal of Modern Energy. Vol. 3, No. 6, 2017, pp. 136-145. doi: 10.11648/j.ajme.20170306.14

Received: October 15, 2017; Accepted: October 31, 2017; Published: December 5, 2017

\begin{abstract}
Oil is extracted from fish and fish by-products by solvent extraction, wet rendering, dry (steam) rendering and wet pressing methods. The method of rendering commonly used in extracting fish oils employs high temperatures, which increase the susceptibility of the extracted oil to thermal degradation. Solvent extraction is not a recommended option for extraction of food-grade fish oils due to the toxic nature of the extraction chemicals. Also, the equipment used for solvent extraction is complex and expensive. Based on this a motorized horizontal screw type fish oil extracting machine is being designed to solve this problem. This machine takes into consideration the dangers, hazards and risks involved in solvent extraction which will be efficient, productive, environmentally friendly, less laborious, easy to use and ergonomic, easy to assemble and disassemble, and most importantly, cost effective in production, maintenance and repairs. The extracting unit consists of an auger with decreasing pitches and a conical choke at the cake exit. The results of the analysis show that the screw press design is safe and the deformations are negligible when the loads are applied.
\end{abstract}

Keywords: Design, Fish Oil, Extraction, Machine

\section{Introduction}

Fish oil is the lipid fraction extracted from fish and fish by-products. Fish oil is different from other oils mainly because of the unique variety of fatty acids it contains, including high level of unsaturated fatty acids. The market for liquid fish oil for human consumption can be divided into three areas: as pharmaceutical component, as a healthy food component, and as a commodity for the food industry. In fish oil, the major free fatty acids (FFA) present are eicosapentaenoic acid (EPA) and docosahexaenoic acid (DHA). There is indication that EPA and DHA exert a positive influence on human health, related to proper neural development, the ability to see and learn, and by modulation of lilosanoids synthesis, decreasing the risk of cardiovascular diseases (arteriosclerosis, thrombosis and stroke), cancers, diabetes, depression, immunity disorders, and other diseases [1]. In principle, fish oil may be used in any food item that contains fats [2]. Fish oils are considered the major commercial source of eicosapentaenoic acid (EPA) and docosahexaenoic acid (DHA) [1], and have received much attention in the scientific and industrial communities because of their positive role in human health [3, 4, and 5].

Fish oil is usually obtained by various extraction techniques. Several studies on methods and conditions for fish oil extraction have been conducted in the past including solvent extraction, wet rendering, dry (steam) rendering and wet pressing methods. Extraction and purification of the lipids by conventional methods, such as hexane extraction, vacuum distillation, or conventional crystallization have the disadvantages of requiring high temperature processing which results in decomposition or degradation of the thermally labile compounds and/or employing toxic solvents having adverse health effects [6]. Therefore, various research efforts are currently focusing on developments in the field of oil extraction and purification technologies. The demands on these processing technologies for extracting and purifying the fish oil are that they are eco-friendly and able to provide high oil yields and to minimize the loss of nutrients and provide a high quality oil [6].

Although the emphasis has been on the marketability of the free fatty acid related health benefits of fish oil, it is known that fish body oil and fish liver oil contain other interesting components, such as vitamin A and D. With 
improved separation techniques and more gentle processing methods, these oils might play an even more important role in the pharmaceutical and food industry in the near future [2]. Hence, the objective of this work is to design fish oil extracting machine that processes at a press temperature of $60^{\circ} \mathrm{C}$ to $80^{\circ} \mathrm{C}$ for optimum oil yield/quality.

\section{Literature Review}

\subsection{Theoretical Considerations}

A mathematical model describing the process of fish oil extraction using mechanical screw press system is desirable. Such a model may be used to establish the limits of the extraction system, as well as evaluate all variables involved, leading to the optimization of the system parameters. The shafts in industrial presses have discrete, non-continuous flights called worm sections.

Figure 1 shows the material flow through a small section of worm channel, that is, the space between the shaft surface and the barrel wall. As the miscella (oil/water) and solid mixture passes through the section, it is subjected to radial pressure exerted by the shaft. The pressure causes flow of miscilla in the radial direction through the solid matrix and out through the barrel slots. This miscella flow in turn changes the flow rate of the mixture in the axial direction.

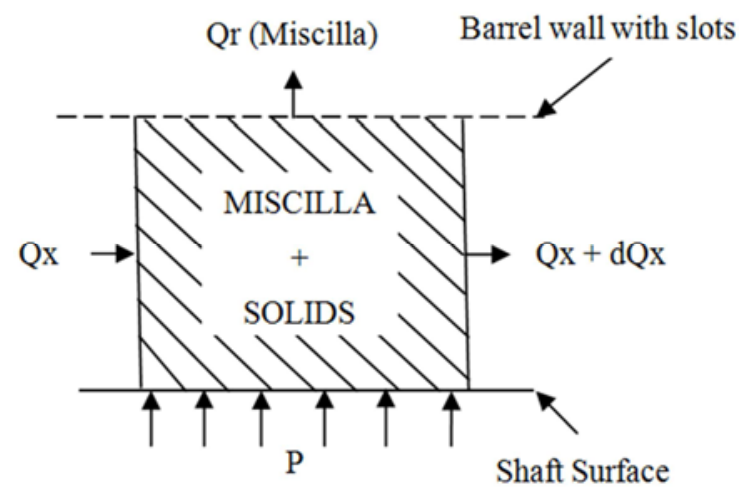

Figure 1. Flow of Material through a Section of Worm Channel.

A material balance along the section gives:

$$
-\mathrm{dQ}_{\mathrm{x}} \rho_{\mathrm{c}}=\mathrm{Q}_{\mathrm{r}} \rho_{\mathrm{l}}
$$

Where; $\mathrm{d}=$ Choke opening $(\mathrm{m}), \mathrm{Q}=$ Flow rates of miscella-solid mixture $\left(\mathrm{m}^{3} / \mathrm{s}\right), \rho=$ Density $\left(\mathrm{kg} / \mathrm{m}^{3}\right), x=$ Direction of worm channel (axial direction), $\mathrm{c}=$ Semi-solid mass (miscella-solid mixture), $\mathrm{r}=$ Radial direction, $1=$ Miscilla (liquid phase).

\subsection{Axial Flow}

The flow through the channel can be described as flow through a rectangular channel as given in equation 2 . The first part of the right hand side of the equation describes the drag flow caused by the rotation of the screw, i.e. the maximum capacity for a given extruder design and screw speed. The second part describes the pressure flow caused by the pressure gradient in the channel. This flow is in the direction opposite to the transport direction of the screw and will therefore reduce the output of the extruder.

The axial flow of a non-Newtonian fluid in an extruder, a machine similar to the mechanical screw press except for the absence of slots in the barrel for outward flow of liquid, has been presented by Shirato et al. [7] as:

$$
\begin{gathered}
Q_{\mathrm{x}}=Q_{\text {drag-leakage }}-Q_{\text {pressure }}=\frac{\pi D W(\mathrm{H}-\delta) \mathrm{Nf}_{\mathrm{d}} \cos \theta}{2}- \\
\left(\frac{\mathrm{H}^{3} \mathrm{Wf} \mathrm{pd}_{\mathrm{ps}}}{12 \mathrm{n} \mu_{\mathrm{c}}}\right) \frac{\mathrm{dP}}{\mathrm{dX}}
\end{gathered}
$$

Where; $\mathrm{Q}_{\mathrm{x}}=$ Flow rate of miscella-solid mixture in screw press $\left(\mathrm{m}^{3} / \mathrm{s}\right), Q_{\text {drag-leakage }}=$ drag flow minus leak flow $\left(\mathrm{m}^{3} / \mathrm{s}\right), Q_{\text {pressure }}=$ pressure flow $\left(\mathrm{m}^{3} / \mathrm{s}\right), \mathrm{D}=$ Barrel diameter (m), $\mathrm{W}=$ Flight width $(\mathrm{m}), \mathrm{H}=$ Flight depth $(\mathrm{m}), \delta=$ Clearance between shaft flight and barrel surface $(\mathrm{m}), \mathrm{N}=$ Speed of shaft rotation (rpm), $\theta=$ Helix angle (degrees), $\mathrm{f}_{\mathrm{d}}=$ Shape factor for drag flow (dimensionless) $=1-$ $\left(0.487 n^{2}-0.948 n+0.972\right) \frac{H}{W}, f_{p s}=$ Shape factor for pressure flow (dimensionless) $=1-\left(0.949 n^{2}-1.87 n+\right.$ 1.59) $\frac{\mathrm{H}}{\mathrm{W}}, \mathrm{f}_{\mathrm{pd}}=$ Correction factor for average viscosity in pressure flow (dimensionless) $=0.98$ (for the region of interest), $\mathrm{n}=$ Power-law index of semi-solid (dimensionless), $\mu=$ Viscosity (Pa s), P = Pressure exerted by the shaft (Pa), X $=$ Distance along the worm channel $(\mathrm{m})$.

\subsection{Pressure at the Choke}

The pressure drop over the choke is calculated with equation which describes the pressure drop of a power law fluid in a circular tube. When the pressure drop over the choke is too high, the throughput is too high and has to be lowered. If the pressure drop over the choke is too low, the throughput has to be increased.

$$
\left(\frac{\mathrm{Q}_{\mathrm{x}}}{\pi \frac{\mathrm{n}}{1+3 \mathrm{n}}\left(\frac{\mathrm{d}_{1}}{2}\right)^{\frac{1+3 \mathrm{n}}{\mathrm{n}}}}\right)^{\mathrm{n}}=\frac{\Delta \mathrm{P}_{\text {choke }}}{2 \mathrm{KL}}
$$

Where; $\mathrm{d}_{1}=$ choke diameter $(\mathrm{m}), \Delta \mathrm{P}_{\text {choke }}=$ Pressure drop over the choke $(\mathrm{Pa}), \mathrm{L}=$ choke length $(\mathrm{m}), \mathrm{K}=$ consistency index paste viscosity $\left(\mathrm{kg} /\left(\mathrm{m} \cdot \mathrm{s}^{2-\mathrm{n}}\right)\right.$.

\subsection{Oil Expression}

Expression of slurries generally consists of two main stages: filtration and consolidation. Whenever free-flowing particles are present, the operation is called filtration. From the point where all the solids form a solids bed onwards, the operation is called consolidation.

Filtration: Equation 4 would be applicable to axial flow in a fish oil press if the miscella-solid mixture is treated as a non-Newtonian fluid. The outward flow of oil has been presented by the expression of equations for variable pressure condition by Shirato et al. [7]. Alternatively, the flow can be presented by the basic filtration equation:

$$
Q_{r}=\pi D d X u_{r}=\pi D d X \frac{P}{\left(\alpha_{s} \mu_{l} m_{s}\right)}
$$

Where; $u=$ Velocity of oil flow at the barrel surface $(\mathrm{m} / \mathrm{s})$, 
$\alpha=$ Specific filtration resistance $(\mathrm{m} / \mathrm{kg}), \mathrm{m}_{\mathrm{s}}=$ Mass of solids in worm channel per unit area of barrel $\left(\mathrm{kg} / \mathrm{m}^{2}\right), \mathrm{s}=$ Solid phase, $1=$ Liquid phase (Miscella).

Combining the material balance across a small section of the barrel with the basic filtration equation, the following equation was obtained;

$$
\frac{\mathrm{dQ}_{\mathrm{x}}}{\mathrm{dX}}=\left[\pi \mathrm{D} \frac{\mathrm{P}}{\left(\alpha_{\mathrm{s}} \mu_{\mathrm{l}} \mathrm{m}_{\mathrm{s}}\right)}\right]\left(\frac{\rho_{\mathrm{l}}}{\rho_{\mathrm{c}}}\right)
$$

Equations 2 and 5 can be used to evaluate the through-put and the oil expression rate provided the pressure developed in the press is known. The pressure development occurs because of the presence of the end restriction at the choke, and is given by:

$$
\mathrm{P}=\mathrm{K}_{\mathrm{c}} \mathrm{K}_{\mathrm{d}} \mathrm{Q}_{\text {choke }}^{\mathrm{n}}
$$

Where; $\mathrm{K}_{\mathrm{c}}=\mathrm{A}$ constant $\left(\mathrm{Pa} \mathrm{s}^{\mathrm{n}}\right), \mathrm{K}_{\mathrm{d}}=$ Choke geometric constant $(\mathrm{l} / \mathrm{m})^{\mathrm{n}}, \mathrm{n}=$ Power-law index of semi-solid (dimensionless), $\mathrm{Q}_{\text {choke }}=$ Flow rate of miscella-solid mixture at choke of the screw press $\left(\mathrm{m}^{3} / \mathrm{s}\right)$.

Consolidation: The behaviour which controls this system has been described in Terzaghi's theory. According to this theory, when a saturated medium, characterized by a low coefficient of permeability, is subject to a compressive force, the pressure of the fluid present in the pores of the medium rapidly increases and then decreases, after a certain period of time, as a result of the extrusion of fluid through the pores. The variation in the pressure of the fluid present in the pores, according to Terzaghi's theory, is proportional to the variation in the hydraulic gradient $[8,9]$.

$$
\frac{\delta u}{\delta t}=C \frac{\delta^{2} u}{\delta z^{2}}
$$

Where; $\mathrm{u}=$ pressure of the fluid inside the compressed medium, $\mathrm{z}=$ depth of the medium, $\mathrm{t}=$ compression time and $\mathrm{c}=$ coefficient of consolidation of the compressed medium defined as:

$$
C=\frac{K}{\mathrm{~m}_{\mathrm{v}} \rho_{\mathrm{f}}}
$$

Where; $\rho_{\mathrm{f}}$ is the oil unit density, $\mathrm{m}_{\mathrm{V}}$ is the coefficient of volume change and $\mathrm{k}$ is the coefficient of permeability calculated as:

$$
K=\frac{Q H}{\Delta \mathrm{hA}_{\mathrm{d}}}
$$

Where; $\mathrm{Q}$ is fluid infiltration rate or flow in the medium, $\mathrm{H}$ is height of the medium, $\Delta \mathrm{h}$ is loss of pressure through the medium, $A_{d}$ is the area of drainage of the fluid; while $m_{v}$ is defined as:

$$
\mathrm{m}_{\mathrm{v}}=-\frac{1}{V} \frac{d V}{d U}=-\frac{1}{H} \frac{d H}{d U}=\frac{d \varepsilon_{Z}}{d \sigma_{z}}
$$

Where; $\mathrm{V}=$ volume of the sample, $\mathrm{dU}=$ change in applied pressure, $d \varepsilon_{z}=$ increment of vertical strain under uniaxial compression, $d \sigma_{z}=$ increment of applied vertical stress under uniaxial compression.

\subsection{Rate of Heat Generation}

The rate of heat generation at steady state (q) was determined from the energy balance equation.

$$
\mathrm{m}_{\mathrm{s}} \mathrm{c}_{\mathrm{s}}\left(\mathrm{T}_{\mathrm{s}}-\mathrm{T}_{\mathrm{r}}\right)+\mathrm{q}=\mathrm{m}_{\mathrm{c}} \mathrm{c}_{\mathrm{c}}\left(\mathrm{T}_{\mathrm{c}}-\mathrm{T}_{\mathrm{r}}\right)+\mathrm{m}_{\mathrm{o}} \mathrm{c}_{\mathrm{o}}\left(\mathrm{T}_{\mathrm{o}}-\mathrm{T}_{\mathrm{r}}\right)
$$

Where; $\mathrm{m}_{\mathrm{s}}=$ Mass flow rate of fish sample $(\mathrm{kg} / \mathrm{s}), \mathrm{m}_{\mathrm{c}}=$ Mass flow rate of cake $(\mathrm{kg} / \mathrm{s}), \mathrm{m}_{\mathrm{o}}=$ Mass flow rate of oil (miscella) $(\mathrm{kg} / \mathrm{s}), \mathrm{c}_{\mathrm{s}}=$ Specific heat capacity of fish sample $(\mathrm{J} / \mathrm{kg} / \mathrm{K}), \mathrm{c}_{\mathrm{c}}=$ Specific heat capacity of fish cake $(\mathrm{J} / \mathrm{kg} / \mathrm{K}), \mathrm{c}_{\mathrm{o}}=$ Specific heat capacity of oil $(\mathrm{J} / \mathrm{kg} / \mathrm{K}), \mathrm{T}_{\mathrm{r}}=$ Reference temperature (taken to be $28^{\circ} \mathrm{C}$ ), $\mathrm{T}_{\mathrm{S}}=$ Temperature of fish sample $\left({ }^{\circ} \mathrm{C}\right), \mathrm{T}_{\mathrm{c}}=$ Temperature of cake $\left({ }^{\circ} \mathrm{C}\right), \mathrm{T}_{\mathrm{o}}=$ Temperature of oil $\left({ }^{\circ} \mathrm{C}\right)$. Heat loss to the surroundings has been assumed to be negligible.

\section{Materials and Methods}

\subsection{Description of the Fish Oil Machine}

The isometric drawing of the fish oil extractor is presented in Figure 2. The machine consists of four segments; the feeding segment, extraction segment, power segment and the frame. The feeding segment consists of the hopper; the extraction chamber consists of the worm shaft, the perforated barrel and the conical restrictor; the power segment consists of the prime mover and the pulley while the frame serves as a support or stand for the machine on which all other segments were mounted.

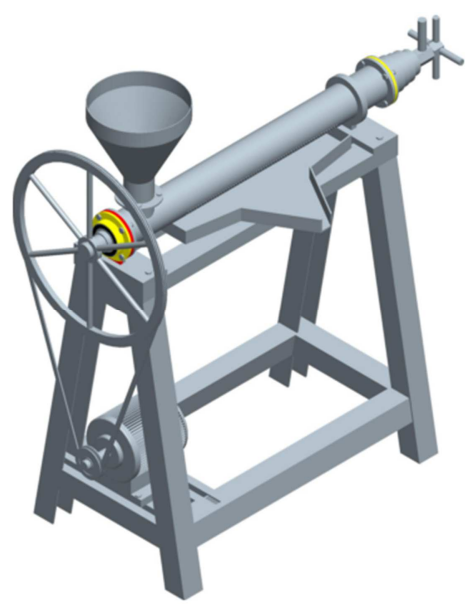

Figure 2. Isometric Drawing of the Fish Oil Extractor.

The worm shaft rotates in the barrel and conveys the fish from the feeding section towards the discharge section where there is a conical restrictor to force the caked fish out of the machine. The maximum compression ratio achieved by the machine is the ratio of intake to the rate of discharge at the conical restrictor (this is $100 \mathrm{~mm}: 20 \mathrm{~mm}$ ). The oil extracted is collected at the oil collection tray and the cake is discharged from the tip of the conical restrictor. Pressure is achieved in the machine by the operation of the worm shaft which was designed to have a decreasing pitch thus reducing the area available for the fish in the barrel. 


\subsection{Determination of Engineering Properties of Fish Sample}

\subsubsection{Density of Fish Sample}

The solid density is the ratio of mass sample of the fish to its solid volume. It was determined by the water displacement method.

$$
\rho=\frac{\mathrm{M}_{\mathrm{f}}-\mathrm{M}_{\mathrm{o}}}{\mathrm{v}}
$$

Where; $\rho=$ Density $\left(\mathrm{kg} / \mathrm{m}^{3}\right), \mathrm{M}_{0}=$ Mass of cylinder $(\mathrm{kg})$, $\mathrm{M}_{\mathrm{f}}=$ Mass of cylinder and fish sample (kg), $\mathrm{V}=$ Volume of fish sample $\left(\mathrm{m}^{3}\right)$.

\subsubsection{Coefficient of Static Friction}

The static coefficient of friction was determined with stainless steel sheet surface using the inclined plane method. This involved placing the fish sample on an adjustable tilting surface equipment with the surface formed using a stainless steel sheet. Manually, the inclination of the plate was increased gradually until the specimen starts to slide down and at that point, the angle of tilt $\alpha$ in degree was read on a graduated scale (protractor).

$$
\mu=\tan \alpha
$$

Where, $\mu=$ Coefficient of friction, $\alpha=$ Angle of tilt in degrees.

\subsubsection{Shear Strength of Fish Sample}

The determination of shear strength was carried out on fish slices $(3 \mathrm{~cm} \times 3 \mathrm{~cm} \times 3 \mathrm{~cm})$. Instrumental determination of shear strength was performed using a TA. XT2 Texture Analyzer (Stable Micro Systems, Hasle-mere, Surrey, UK). All instrumental measurements were carried out at a deformation rate of $2 \mathrm{~mm} / \mathrm{s}$. A flat ended cylinder attachment of $20 \mathrm{~mm}$ in diameter was applied on the fish fillets. The penetration depth and the speed was expressed as the force $(\mathrm{N})$ necessary for the probe to penetrate each sample and a force-distance curve was plotted from the results. The forces necessary to penetrate each sample was read from the curve at a penetration depth of $5.00,6.25$, and $7.50 \mathrm{~mm}$ and at the yield point. The yield point was described as the first abrupt change in the slope in the force-distance curve or the first breaking point in the sample, occurs when the probe causes irreversible crushing in the muscle. The yield point is regarded as the toughness of the fillet, while the resistance of the muscle fibers against compression (maximum force) expresses hardness.

\subsection{Initial Design Concepts}

Two major aspects of the overall design are a pressure generating mechanism and a fish oil/cake separation technique. The following concepts explore these different requirements.

\subsubsection{Pressure Generating Concepts}

Although there are many aspects of this machine that need to be considered, first and foremost it must be able to create pressures capable of extracting oil. Consequently, the initial design concepts focused on exploring force generating mechanisms that could then be further developed and incorporated into an entire machine.

\section{A. Screw shaft}

During the study, various types of screw shaft configurations have been developed and considered. Some of these configurations are used in conventional screw presses. Some basic configurations of screw shafts are presented below [10].

Straight screw shaft: In the straight screw shaft, the screw pitch and the root diameter are constant through the screw shaft. The rate of pressure increase in this type of a screw press is analogues to the rate of pressure increase in hydraulic presses. The type of screw shaft configuration is commonly used in screw presses, because the manufacturing process is easy.

Screw with tapered shaft: In this type of screw shaft, the pitch is constant, where the annular area is decreasing through the length of the screw and takes its minimum value at the end of the screw. The volume swept by the screw thread in each turn is the multiplication of the annular area and the pitch distance. In this type of screw shaft, the rate of pressure increase is higher than straight screw shaft. Besides, machining of this part requires a CNC machine.

Screw with variable pitch: This is a screw type with decreasing pitch. This type of a screw thread can only be machined with a 5-axes CNC machine tool. So, in order to reduce the cost, total shaft is separated into several sections. Each section has a constant pitch, but different from the pitch of the other. The screw, through which the materials are fed, has the maximum pitch in order to increase the material capacity. Similar to the tapered shaft system, in this type of screw shaft system, volume is decreased by an amount in each turn. The main difference between them is the rate of pressure increase through each thread. In tapered screw, pressure increase linearly through the screw shaft whereas in screw with variable pitches distance, pressure is constant through each thread and increase at the transitions. Figure 3 shows the screw shaft configurations.

Screw with tapered shaft and variable pitch: This is the combination of the screw types with variable pitch and tapered shaft. Rate of pressure increase in this type of screw is higher when compared with the other type of screws. The same pressure can be determined in a shorter time because the pressure attains its maximum value in fewer revolutions when compared with the same sized screw types.

Screw with reverse worm: Screw with reverse worm configuration is different from the previous ones; screw is composed of more than three pieces depending on the number of reverse worms. Reverse worms are generally used to reduce the total compression ratios, in other words, the same amount of oil can be obtained at lower pressure values by using reverse worms at different locations. Maximum required pressure is decomposed into smaller values by compressing the oil bearing materials at more than one stage. 


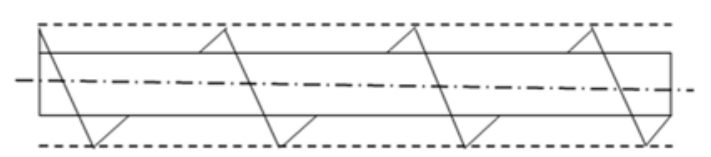

(a) Straight screw shaft

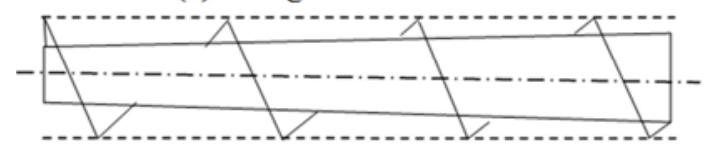

(b) Screw with tapered inner shaft

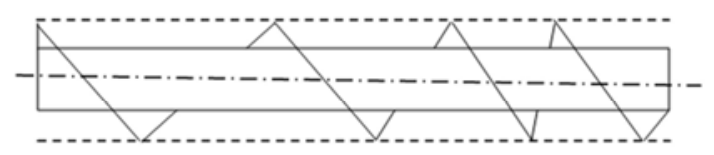

(c) Screw with variable pitch

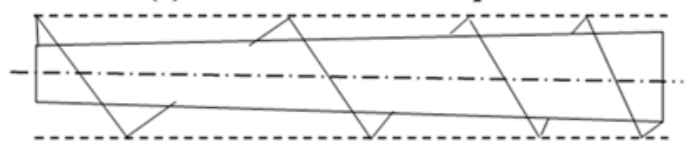

(d) Screw with tapered shaft and variable pitch

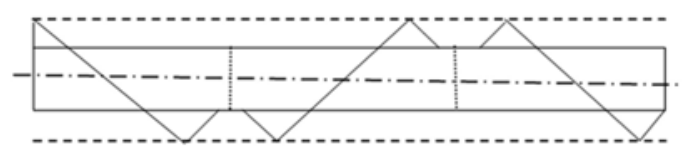

(e) Screw with reverse worms

Figure 3. Screw Shaft Configurations.

\section{B. Choke mechanism}

The common property of cake drainage systems in screw presses is the adjustability of the cake drainage opening. Narrower openings result in low residual oil content in the cake. Also, the opening size depends on the type of the oil bearing material. During the study, various types of cake drainage systems are considered. Working principles of these cake drainage systems are presented below [10].

Nozzle type choke mechanism: Generally, in small types of screw presses, nozzle type choke mechanism is used. In nozzle type choke mechanisms, one end of the screw shaft is free and the other end has two bearings. The screw shaft is short enough to compensate any deformation arising from buckling. Oil bearing materials continue to accumulate at the end of the screw until the maximum pressure has been reached. During compression, oil part of the materials leaks from the filter and the left cake starts to extrude out from the nozzle, at the end of the screw. Besides, the required maximum pressure can be provided by adjusting the nozzle diameter. In this type of choking mechanism, the maximum pressure at the end of the screw pushes the screw backward. The resultant force is the multiplication of the axial component of the maximum pressure and the circular area of the screw. Since the application area of the back force is comparatively larger than in conical type of choke mechanisms, bearing which carries the axial back force should be larger in this type of systems. Another disadvantage for this choking system is the probability of a blockage at the entrance of the nozzle.

Conical type of choke mechanism: This type of a system is both practical and economical when compared with the equivalent systems. The maximum pressure and the cake thickness can be changed by adjusting axial displacement of the screw shaft forward and backward in order to achieve the required pressure. The force pushing the screw backward is relatively less here when compared with the nozzle type choke mechanism since the effective pressure area is less than the normal cross-section. Figure 4 shows the types of choke mechanisms.

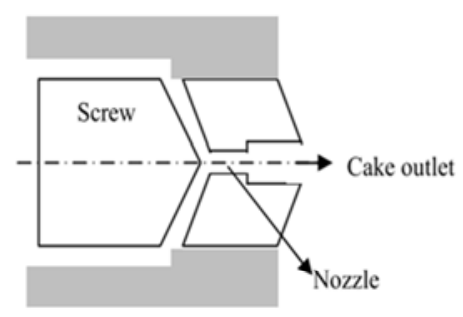

(a) Nozzle Type Choke Mechanism

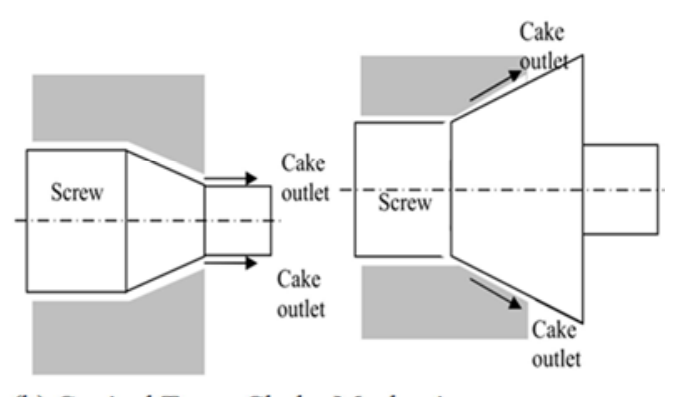

(b) Conical Types Choke Mechanisms

Figure 4. Choke Mechanisms [10].

\subsubsection{Oil and Meal Separation Concepts}

One of the greatest challenges encountered in edible oil extraction is separating the oil from the meal. It is not enough to press the fish momentarily with high pressure; instead, there must be continuous pressure on the fish in order to successfully extract oil. If the fish are pressed and then the pressure is quickly removed, there is a risk of the oil being reabsorbed by the cake. There are three typical systems used in commercial screw presses for oil drainage which are presented below [10].

Drilled holes: This type of oil drainage system has circular holes on the vessel for oil drainage. The main advantage of this system is no extra part for oil drainage system is required. However the oil drainage openings in this system are not adjustable.

Lining bars with spacers: In this type of oil drainage system, lining bars are fixed inside surface of the vessel cage. Spring type metal spacers are placed between two bars. Different sizes of gaps can be obtained by using spacers in different thicknesses. Also, in this system, lining bars canalize the compressed materials to move forward. This system prevents jamming by creating obstacles to the rotating compressed oil bearing materials, so that the materials are pushed forward more strongly.

Fiber filter sleeves: This kind of liquid drainage system is generally used for the substances which do not require high pressure. Since the fiber is a deformable material, high 
pressures would result in expansion of the fiber.

Barrel rings: In this type of oil drainage system, the vessel is made up of barrel rings with triangular barrels. The barrel rings are separated by circular spacers, that slide onto the tie bars to form the drained barrel of the press. This arrangement offers greater flexibility to adjust the drainage gaps of the press and forms a very simple assembly that can be easily maintained.

\subsection{Final Design of the Fish Oil Extractor}

After evaluating the various pressure generating concepts, it was decided to proceed with the lead screw design would be most promising. The straight screw type with variable pitch, conical type choke mechanism and drilled holes type oil drainage system were selected due to simplicity and cost considerations.

\section{Design Considerations}

The following were considered in the design of the fish oil extractor:

i. The machine was designed with pulley as a means of speed reduction mechanism in place of a gear box and powered by electric motor. This is to make it affordable to the processors.

ii. The screw pitch was designed to enhance pressure development and reduce clogging by reducing the screw pitch from the feed point to the discharge point.

iii. The long screw length was adopted so as to get appreciable oil recovery in the expression process [11, 12].

\subsection{Machine Components Design}

\subsubsection{Design of the Worm (Screw) Shaft of the Expeller}

The diameter of the shaft was determined from the equation $[13,14,15]$.

$$
\begin{aligned}
\mathrm{d}_{\mathrm{s}}{ }^{3} & =\frac{16 \mathrm{~T}}{0.27 \pi \delta_{0}} \\
\text { But } \mathrm{T} & =\frac{60 \mathrm{P}}{2 \pi \mathrm{N}}
\end{aligned}
$$

Where, $d_{s}$ is diameter of the screw shaft, $T$ isthe torque transmitted by the shaft, $\delta_{0}$ isthe yield stress for mild steel $\left(200 \mathrm{~N} / \mathrm{mm}^{2}\right), \mathrm{P}=$ Power rating of the motor $=3.73 \mathrm{~kW}(5 \mathrm{hp})$, $\mathrm{N}=$ Screw shaft speed $=70 \mathrm{rpm}$. Hence, $\mathrm{T}=508.84 \mathrm{Nm}$ and $\mathrm{ds}=36.34$. The nearest available shaft size $51 \mathrm{~mm}$ diameter and $1200 \mathrm{~mm}$ length was used.

\subsubsection{Screw Design Geometry}

A. Determination of the pitches of the decreasing pitch screw conveyor

The screw conveyor is the main component and most functional unit of the extraction chamber. The American Society of Agricultural Engineers (ASAE) engineering practice states that the pitch of the flighting of auger conveyors should be between 0.9 and 1.5 times the outside diameter of the flighting. The most economical pitch is equal to the flighting outside diameter. Therefore, the first pitch of the decreasing pitch auger was taken be equal to the outer diameter of the screw shaft; $P_{s}=D_{s}=86 \mathrm{~mm}$. In determination of the pitches of decreasing order, iteration method was used. A value was assumed for the first pitch (P) in other to obtain a value for the inlet velocity $(\mathrm{v})$ and then evaluate the remaining pitches using iteration. The summation of the pitches must not be greater than the total length of the conveyor $(1200 \mathrm{~mm})$. The inlet velocity of raw material, $\mathrm{V}$ was determined from;

$$
V=\frac{P_{S} \times \frac{\pi}{4}\left(D_{S}^{2}-d_{S}^{2}\right) N}{4 D L}
$$

Where; $P_{s}$ is the screw pitch, $D$ is the outside diameter of screw, $d$ is the inside diameter of screw, $L$ is the length of the screw shaft, and $\mathrm{N}$ is the shaft speed. Given that $\mathrm{P}_{\mathrm{s}}=86 \mathrm{~mm}$, $\mathrm{D}=86 \mathrm{~mm}, \mathrm{~d}=51 \mathrm{~mm}, \mathrm{~L}=1200 \mathrm{~mm}, \mathrm{~N}=70 \mathrm{rpm}$. Inlet velocity $\mathrm{V}=55 \mathrm{~mm} / \mathrm{s}$

The remaining screw pitches were designed using the expression;

$$
\mathrm{P}_{\mathrm{S}}=\frac{4 \mathrm{VDL}}{\frac{\pi}{4}\left(\mathrm{D}_{\mathrm{S}}^{2}-\mathrm{d}_{\mathrm{S}}^{2}\right) \mathrm{N}}
$$

The second pitch was calculated as;

$\mathrm{P}_{\mathrm{s}}=\frac{4 \mathrm{VDL}_{2}}{\frac{\pi}{4}\left(\mathrm{D}_{\mathrm{s}}^{2}-\mathrm{d}_{\mathrm{s}}^{2}\right) \mathrm{N}}=\frac{4 \times 55 \times 86(1200-86)}{\frac{\pi}{4}\left(86^{2}-51^{2}\right) 70}=80 \mathrm{~mm}$

The third pitch was calculated as;

$$
\mathrm{P}_{\mathrm{s}}=\frac{4 \mathrm{VDL}_{3}}{\frac{\pi}{4}\left(\mathrm{D}_{\mathrm{s}}^{2}-\mathrm{d}_{\mathrm{s}}^{2}\right) \mathrm{N}}=\frac{4 \times 55 \times 86(1114-80)}{\frac{\pi}{4}\left(86^{2}-51^{2}\right) 70}=74 \mathrm{~m}
$$

Therefore; screw pitches: $86,80,74,69,64,59,55,51,48$, $44,41,38,35,33,30,28,26$ and $24 \mathrm{~mm}$, making a screw length of $885 \mathrm{~mm}$ on a shaft of length $1300 \mathrm{~mm}$ with mean of $49 \mathrm{~mm}$.

\section{$B$. The length of a screw winding}

The length of the screw winding, L was obtained using Pythagoras rule as the square root of the sum of squares of the circumference, $\mathrm{C}$ of the shaft diameter and the screw pitch, $\mathrm{P}_{\mathrm{s}}$.

$$
\mathrm{L}=\sqrt{\mathrm{C}^{2}-\mathrm{P}_{\mathrm{S}}^{2}}
$$

Circumference of the $51 \mathrm{~mm}$ diameter shaft $=\pi \mathrm{d}=160 \mathrm{~mm}$

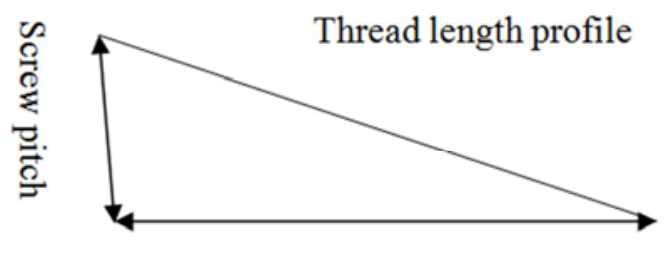

Shaft circumference

Figure 5. How to generate thread profile.

Thread length for the first pitch of $86 \mathrm{~mm}$ will be, $\mathrm{L}=$ $\sqrt{160^{2}+86^{2}}=182 \mathrm{~mm}$; Thread length for the second pitch of $80 \mathrm{~mm}$ will be; $\mathrm{L}=\sqrt{160^{2}+80^{2}}=179 \mathrm{~mm}$. Therefore; screw thread lengths: $182,179,176,174,172,171,169,168$, $167,166,165,164,164,163,163,162,162$ and $162 \mathrm{~mm}$, 
making a total screw winding of length $3029 \mathrm{~mm}$.

C. Distance between axes of flight screw

Distance between axes of flight screw was obtained from the equation [16];

$$
\frac{\mathrm{a}}{\mathrm{D}_{\mathrm{s}}} \leq \frac{\sqrt{2}}{2}
$$

Where; $\mathrm{D}_{\mathrm{s}}=$ barrel diameter $=88 \mathrm{~mm} . \mathrm{a}=62 \mathrm{~mm}$

\section{Maximum flight height}

Maximum flight height (channel depth), $\mathrm{h}_{\max }$ was calculated according to Fadeyibi et al. [16] as;

$$
\begin{aligned}
\mathrm{h}_{\max } & =\mathrm{D}_{\mathrm{s}}-\mathrm{a} \\
\mathrm{h}_{\max } & =26 \mathrm{~mm}
\end{aligned}
$$

\section{E. Helix angle (pitch angle)}

The helix angle (angle of pitch) at the barrel surface, $\alpha$, which is related to lead and diameter is given by the equation $[17,18]$;

$$
\alpha=\tan ^{-1}\left(\frac{P}{\pi D_{s}}\right)
$$

Where; $\mathrm{P}=$ Mean screw pitch (lead) $=49 \mathrm{~mm}, \alpha=10^{0}$

\section{F. Maximum flight width}

The maximum flight width, $\mathrm{t}_{\max }$ was computed from the formula [16];

$$
\mathrm{t}_{\max }=\mathrm{P} \beta\left(\frac{\cos \alpha}{2 \pi}\right)
$$

Where; $\beta=$ Flight angle $(\mathrm{rad})=90^{\circ}=1.57 \mathrm{rad} . \mathrm{t}_{\max }=12$ $\mathrm{mm}$

\subsubsection{Load that Can Be Lifted by the Screw}

The load that can be lifted by the screw was determined from the equation [14];

$$
\begin{aligned}
\mathrm{W} & =\frac{\mathrm{P}}{\tan (\alpha+\theta)} \\
\text { But } \mathrm{P} & =\frac{2 \mathrm{~T}}{\mathrm{D}_{\mathrm{m}}} \\
\text { And } \theta & =\tan ^{-1} \mu
\end{aligned}
$$

Where, $\mathrm{W}=$ load that can be lifted by screw, $\mathrm{P}=$ effort applied at the circumference of the screw to lift the load, $\alpha=$ helix angle, $\theta=$ angle of friction, $\mathrm{T}=$ torque transmitted $(508.84 \mathrm{Nm}), \mathrm{D}_{\mathrm{m}}=$ screw mean diameter $(68.5 \mathrm{~mm}), \mu=$ coefficient of friction (0.466). Therefore, $\mathrm{W}=21,217.48 \mathrm{~N}$

\subsubsection{Pressure to Be Developed by the Screw Thread (Flight)}

The pressure developed by the screw thread was determined by equations given by Hall et al. [19] as:

$$
\begin{aligned}
\mathrm{P}_{\mathrm{r}} & =\frac{\mathrm{W}}{\mathrm{A}_{\mathrm{p}}} \\
\text { But } \mathrm{A}_{\mathrm{p}} & =\pi \mathrm{D}_{\mathrm{m}} \mathrm{nh}
\end{aligned}
$$

Where, $\mathrm{P}_{\mathrm{r}}=$ pressure developed by the screw thread, $\mathrm{W}=$ load that can be lifted by the screw, $A_{P}=$ pressing area, $D_{m}=$ mean thread diameter $(68.5 \mathrm{~mm}), \mathrm{n}=$ number of screw turns (18) and $\mathrm{h}=$ screw depth at the maximum pressure area or discharge end $(17.5 \mathrm{~mm})$, hence $A_{P}=67,796.51 \mathrm{~mm}^{2}$ and $\mathrm{Pr}=$ $0.31 \mathrm{~N} / \mathrm{mm}^{2}$. Therefore, a pressure of $0.31 \mathrm{Mpa}$ would be available for pressing and squeezing oil from the fish during operation.

\subsubsection{Capacity of the Worm Shaft of the Expeller}

The processing capacity of the fish oil expeller was taken as the capacity of the screw conveyor which is the main functional unit of the extraction chamber of the extractor. Hence, the capacity of the horizontal acting auger conveyor was computed using the equation[14, 20];

$$
Q_{e}=60 \frac{\pi}{4}\left(D_{s}^{2}-d_{s}^{2}\right) P_{s} N_{s} \varphi \rho
$$

Where, $Q_{e}$ is the theoretical capacity of the expeller $(\mathrm{kg} / \mathrm{hr}), D_{s}$ is the outer diameter of the screw shaft $(86 \mathrm{~mm})$, $d_{s}$ is the base diameter of the screw shaft $(51 \mathrm{~mm}), P_{s}$ is the mean screw pitch $(49 \mathrm{~mm}), N_{s}$ is therotational speed of the screw shaft $(70 \mathrm{rpm}), \varphi$ is the factor induced for horizontal conveyor (1) and $\rho$ is the bulk density of the fish sample (950 $\left.\mathrm{kg} / \mathrm{m}^{3}\right)$. Hence $Q_{e}=736.38 \mathrm{~kg} / \mathrm{hr}$.

\subsubsection{Pressurize Cone}

This is made of mild-steel material of the base dimension of $86 \mathrm{~mm}$, height of $80 \mathrm{~mm}$, and bore size of $52 \mathrm{~mm}$ of cone shape. It is mounted on the shaft at the end of the screw flight to pressurize the fish effectively. Their linear displacement is control by adjustable nuts that determine the extraction ratio.

Weight $=$ density $\times($ volume of cone - volume of bore $)$

$$
\mathrm{W}=\rho \times\left(\frac{1}{3} \pi\left(\mathrm{R}^{2}+\mathrm{r}^{2}+\mathrm{Rr}\right) \mathrm{h}-\pi \mathrm{r}^{2} \mathrm{~h}\right)
$$

Where; $\mathrm{R}=43 \mathrm{~mm}, \mathrm{r}=26 \mathrm{~mm}, \mathrm{~h}=80 \mathrm{~mm}, \mathrm{~W}=1.06 \mathrm{~kg}=$ $10.40 \mathrm{~N}$

\subsubsection{Press Cage (Barrel) Design}

The press cage (barrel) has a big hole for feeding oil bearing material. This feeding hole is machined at the beginning of the screw shaft at where the screw pitch is maximum. On the mid zone, the barrel carries oil outlet sieve. The region of the outlet is slightly recessed by $3 \mathrm{~mm}$, by boring, to prevent the excessive back flow of oil from the caking or pressing region into the incoming feed. The oil drainage zone is slightly far from the cake drainage zone which is the maximum pressure zone. The reason is that, these small holes are filled and choked with compressed cake at high pressure levels.

For proper oil extraction, a clearance of $1 \mathrm{~mm}$ is appropriate between screw thread and internal wall of the press cage. Therefore, inner diameter of the press cage was determined as:

$$
\mathrm{D}_{\mathrm{I}}=\mathrm{D}+2 \mathrm{C}
$$

Where; $\mathrm{D}_{\mathrm{I}}$ is the inner diameter of the press cage, $\mathrm{D}$ is the screw shaft diameter $(86 \mathrm{~mm})$ and $\mathrm{C}$ is the clearance between the internal wall of press cage and screw thread $(1 \mathrm{~mm}) . \mathrm{D}_{\mathrm{I}}=$ $88 \mathrm{~mm}$. 
The outer diameter of the press cagewas determined by the equation below as:

$$
\mathrm{D}_{\mathrm{I}}=0.95 \mathrm{D}_{0}
$$

Where, $\mathrm{D}_{0}$ is the outer diameter of the press cage in $\mathrm{mm}$. $\mathrm{D}_{0}=93 \mathrm{~mm}$.

The thickness of the press cage was determined thus:

$$
\mathrm{t}=\mathrm{D}_{0}-\mathrm{D}_{\mathrm{I}}
$$

Where, $\mathrm{t}$ is the thickness of the press cage in $\mathrm{mm}$. $\mathrm{t}=5$ $\mathrm{mm}$. Therefore, a mild steel pipe of diameter $88 \mathrm{~mm}$ and thickness $10 \mathrm{~mm}$ was selected for the press cage of the expeller.

\subsubsection{The Pressure of the Barrel}

The pressure that can be withstood by the barrel was determined by the equation [14];

$$
\mathrm{P}_{\mathrm{b}}=\frac{2 \mathrm{t} \delta_{\mathrm{a}}}{\mathrm{D}_{\mathrm{i}}}
$$

Where, $\mathrm{P}_{\mathrm{b}}=$ pressure to be withstood by the barrel, $\mathrm{t}=$ thickness of barrel $(10 \mathrm{~mm}), \delta_{\mathrm{a}}=$ allowed stress $\left(0.27 \delta_{0}\right), \delta_{0}$ $=$ yield stress of mild steel $\left(200 \mathrm{~N} / \mathrm{mm}^{2}\right)$ and $\mathrm{D}_{\mathrm{i}}=$ inside diameter of barrel $(88 \mathrm{~mm})$. Hence, $\mathrm{P}_{\mathrm{b}}=12.27 \mathrm{Mpa}$. This means that the pressure that the barrel can withstand $(12.27 \mathrm{Mpa})$ is greater than the pressure developed by the screw thread for oil extraction $(0.31 \mathrm{Mpa})$. Therefore, the barrel will withstand the extraction pressure without bursting.

\subsubsection{Design for the Power Requirement of the Screw Press}

In the screw press design there are basically four areas where power is needed; these are: Power required to overcome the inertia of the shaft and screw, Power required to drive and convey the fish along the entire length of the press, Power required to effectively press and squeeze out entrapped oil from the fish and Power compensation for friction and other losses during operation.

i. Power to overcome the inertia of the screw shaft: Power $\left(\mathrm{P}_{\mathrm{i}}\right)$ to overcome the mass of the screw shaft was calculated as;

$$
\mathrm{P}_{\mathrm{i}}=\mathrm{WV}_{\mathrm{s}}
$$

Where; $\mathrm{W}=$ weight of the screw shaft $(\mathrm{N}), \mathrm{V}_{\mathrm{s}}=$ mean peripheral speed $(\mathrm{m} / \mathrm{s})$ of the screw shaft. Weight of screw shaft $=$ weight of shaft + weight of flights + weight of cone

$$
=189.04+72.89+10.40=272.33 \mathrm{~N} .
$$

Speed of screw shaft (Vs) was determined from equation;

$$
\mathrm{V}_{\mathrm{s}}=\frac{\pi \mathrm{DN}}{60}
$$

Where; $\mathrm{V}_{\mathrm{S}}=$ Peripheral Speed $(\mathrm{m} / \mathrm{s}), \mathrm{D}=$ diameter of screw $(86 \mathrm{~mm}), \mathrm{N}=$ Speed of Operating the screw shaft (70rpm), hence $\mathrm{V}_{\mathrm{s}}=0.315 \mathrm{~m} / \mathrm{s}$ and $\mathrm{P}=85.78$ watts

ii. Power to drive the press: The power required to drive the machine was determined using an equation adapted from Onwualu et al. [20] as:

$$
P_{d}=\frac{Q_{V} I_{s} \rho g F}{3.6}
$$

Where; $\mathrm{P}_{\mathrm{d}}=$ power required to drive the press, $\mathrm{Q}_{\mathrm{V}}=$ volumetric capacity of the worm shaft $\left(0.775 \mathrm{~m}^{3} / \mathrm{hr}\right), \mathrm{I}_{\mathrm{s}}=$ length of worm shaft $(1200 \mathrm{~mm}), \rho=$ bulk density of the fish $\left(950 \mathrm{~kg} / \mathrm{m}^{3}\right), \mathrm{g}=$ acceleration due to gravity and $\mathrm{F}$ is = material factor $(0.8)$, hence $P_{d}=1,926.03$ watts.

iii. Power to press the fish (extract oil): With a chosen speed of 70rpm for the expeller shaft and 20:1 revolution of electric motor to expeller shaft. An electric motor capable of producing the speed [14]; $\mathrm{N}=70 \times 20=1400 \mathrm{rpm}$. Power to extract oil is defined by;

$$
\begin{aligned}
\mathrm{P}_{\mathrm{e}} & =\mathrm{T} \omega \\
\text { But } \omega & =\frac{2 \pi N}{60} \\
\text { And } \mathrm{T} & =\frac{\pi(\mathrm{D})^{3} \tau}{16}
\end{aligned}
$$

Where; $\mathrm{P}_{\mathrm{e}}=$ Power required to extract oil (W), $\omega=$ Angular velocity of screw shaft $(\mathrm{rad} / \mathrm{s}), \mathrm{T}=$ Torque of screw shaft in relation with the shear stress of fish $(\mathrm{Nm}), \mathrm{D}=$ Diameter of screw shaft $(0.086 \mathrm{~m}), \tau=$ Shear stress of fish $\left(3578 \mathrm{~N} / \mathrm{m}^{2}\right.$ determined). Hence, $\omega=146.63 \mathrm{rad} / \mathrm{s}, \mathrm{T}=0.447$ $\mathrm{Nm}$ and $\mathrm{P}_{\mathrm{e}}=65.54$ watts.

iv. Power to overcome friction: Power $\left(\mathrm{P}_{\mathrm{f}}\right)$ to overcome friction was calculated as;

$$
\begin{aligned}
\mathrm{P}_{\mathrm{f}} & =\mathrm{FV}_{\mathrm{s}} \\
\text { But } \mathrm{F} & =\mu \mathrm{N}
\end{aligned}
$$

Where; $\mathrm{F}=$ frictional force $(\mathrm{N}), \mathrm{V}_{\mathrm{S}}=$ Peripheral Speed $(0.315 \mathrm{~m} / \mathrm{s}), \mu=$ coefficient of friction $(0.466), \mathrm{N}=$ weight of screw shaft $(272.33 \mathrm{~N})$. Hence, $\mathrm{P}_{\mathrm{f}}=39.98$ watts.

Total Power Required $\mathrm{P}=\mathrm{P}_{\mathrm{i}}+\mathrm{P}_{\mathrm{d}}+\mathrm{P}_{\mathrm{e}}+\mathrm{P}_{\mathrm{f}}=85.78+$ $1,926.03+65.54+39.98=2,117.33$ watts.

The power of the electric motor to drive the screw press was estimated using the equation given by Onwualu et al. [20] below as:

$$
\mathrm{P}_{\mathrm{m}}=\frac{\mathrm{P}}{\eta}
$$

Where, $\mathrm{P}_{\mathrm{m}}=$ power of the electric motor and $\eta=$ drive efficiency (0.8). Hence, $\mathrm{P}_{\mathrm{m}}=2,646.66$ watts $(3.55 \mathrm{hp})$. Therefore, a 5hpsingle-phase electric motor was selected to drive the machine.

\subsection{Analysis of Designed Components}

To validate the designs, analyses of shaft and barrel designs are performed. The oil extractor contains one rotating shaft and the material used is mild steel. When the shaft makes one rotation, the fish progress axially by one pitch and also gets crushed to some extent. On continuous rotation of the shaft, the fish is transported from hopper end to the crushing end. During this movement the fish exert axial and tangential forces on the shaft.

As the fish progress, the screw pitch decreases, which results to pressure increases along the screw shaft. The 
pressure reaches a maximum of $12 \mathrm{MPa}$ at the pressing region. All the loads that are developed are applied on the shaft. The shaft is mounted on bearings. In the analysis, the bearings are substituted by cylindrical supports. The shaft is also subjected to a torque of $600 \mathrm{Nm}$.

The barrel is made from a mild steel pipe and is machined to the exact accuracy and then the analysis is carried out by applying the pressure. The pressure of $12 \mathrm{MPa}$ is applied on the inner region of the barrel assembly. The barrel is fixed on both the end faces.

\section{Results and Discussion}

\subsection{Engineering Properties of Fish Sample}

Engineering properties of fish sample were presented in Table 1. The observed included density, coefficient of friction and shear strength. The density of fish sample was found to be $950 \mathrm{~kg} / \mathrm{m}^{3}$ and the coefficient of friction and the shearing strength were found to be 0.466 and $3578 \mathrm{~N} / \mathrm{m}^{2}$ respectively.

Table 1. Mechanical Properties of Fish Sample.

\begin{tabular}{ll}
\hline Parameter & Test Value \\
\hline Density & $950 \mathrm{Kg} / \mathrm{m}^{3}$ \\
Coefficient of friction & 0.466 \\
Shear Strength & $3578 \mathrm{~N} / \mathrm{m}^{2}$ \\
\hline
\end{tabular}

\subsection{Development of the Conceptual Design}

A small scale fish oil extracting machine has been successfully design. The developed machine has the following main component; feed hopper, screw shaft, barrel, choke regulator, oil tray, prime mover and main frame. Figure 6 shows the main components of the fish oil extractor.

The machine was tested to evaluate its performance. It was expected with this test to verify that the prototype would be capable of dealing with four specific goals related to this initial stage of research: ability to perform the crushing of the oil bearing material evenly generating pie; ability to perform the transport of mass flow consisting of oil and substrate along the compression chamber; ability to perform the separation between oil and the substrate; and finally, capacity to generate fish oil suitable for use both in research and direct consumption.

In the test, the samples deposited at the entrance of the equipment were completely sucked into the compression chamber. About nine minutes after the test, the material expelled by the action of rotation of the auger starts flowing in small quantities by the vents below the cylinder. This material is presented as a mixture between fish substrate and fish oil. The prototype was able to generate a homogeneous mass and pressure drag to perform both the transport of mass and flow as to achieve a separation between oil and substrate thereby producing the fish oil. After 17 minutes of output of material, the 25 minute test ends, with no further changes present, the equipment was turned off.

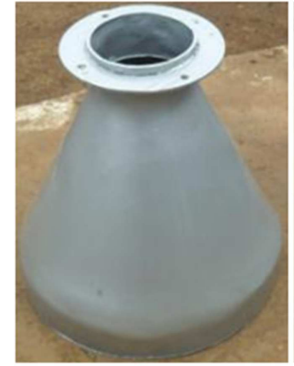

Feed Hopper

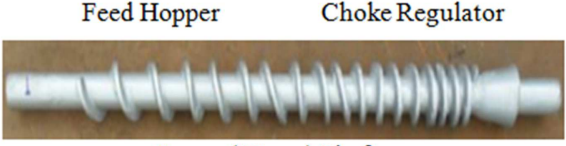

Screw (Worm) Shaft

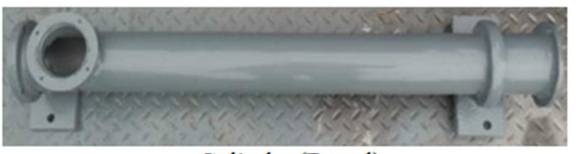

Cylinder(Barrel)

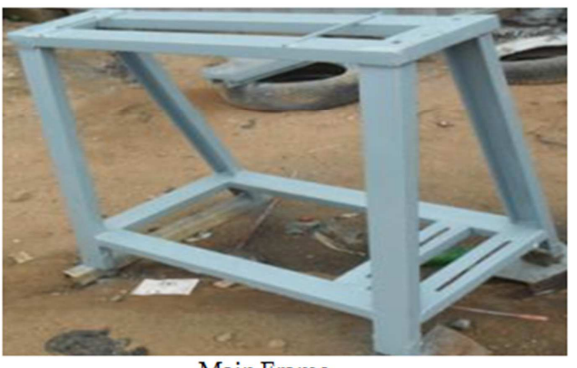

Main Frame

Figure 6. Main Components of the Fish Oil Extractor.

\subsection{Analysis of Designed Components}

The effect of fatigue life is affected by the manufacturing process and component configuration. Several factors such as surface condition, size, stress concentration and temperature are significantly affect fatigue life of materials which is being processed.

Design and validation of dimension of the machine parts are considered. Evaluation of thermal stress analysis through computerized techniques was carried out on designed parts like bearing, main shaft, and worms of oil expeller by applying the similar constraint with respect to material, temperature and loading conditions, to determine the high stressed regions. After stress analysis decision about changes which could be in dimensions and material was taken in order to make the optimal changes to reduce the failures.

The results of the analysis shows that the single screw design is safe and the deformations are negligible when the loads are applied, so in order to meet the growing demands a screw expeller is feasible both economically and technically by decreasing the overall cost of production and by increasing the throughput rate of oil bearing materials.

\section{Conclusion}

In the oil expeller there is a common problem of the failure of spare parts like bearing, main shaft, worm threads, rings, shaft key, gears etc due to the action of high forces and 
various stress on these spare parts, also the generation of the huge amount of heat between mating parts lead to wear of the parts and reduction of their strength, resulting in their failure. The failure of the spares leads to reduction in efficiency and even breakdowns.

In order to reduce these failures, design and analysis of spare parts is necessary, which result in the selection of the optimal parameters for these spares increasing its efficiency and hence the overall productivity of the industry.

In this work some of the components of oil expeller such as main shaft rpm, main shaft diameter and crushing chamber dimensions were designed. Design of all these components matches with the components actually used in oil expeller machine. Therefore we can say that the design components used is safe.

Findings indicate that screw press with straight and variable pitch inner shaft is simpler, more effective and generate more pressures compared with other designs of screw presses. The selection of the screw press with straight and variable pitch inner shaft can reduce initial and maintenance costs, and is easy to clean and maintain. The conical type choke mechanism and drilled holes type oil drainage system were also selected due to simplicity and cost considerations.

Single screw extractor (expeller) can be used for expelling oil from fishes. It can also achieve a throughput rate of 90$120 \mathrm{~kg} /$ hour with single pass. The choice of material and overall cost of machine would encourage mass production and, hence, reduction in price and availability of noncontaminated and non-adulterated fish oil.

\section{References}

[1] B. Hee-Guk, E. Tae-Kil, J. Won-Kyo, and K. Se-Kwon, Characterization of Fish Oil Extracted from Fish Processing Byproducts. Journal of Food Science and Nutrition, 2008, 13: 7-11.

[2] O. D. Adeniyi, Herring Fish (Clupeaharengus) Oil Production and Evaluation for Industrial Uses. Journal of Dispersion Science and Technology, 2006, 27:537-541.

[3] V. Fournier, F. Destaillats, B. Hug, P. A. Golay, F. Joffre and P. Juaneda, Quantification of eicosapentaenoic and docosahexaenoic acid geometrical isomers formed during fish oil deodorization by gas-liquid chromatography. Journal of Chromatography A, 2007, 1154, 353-359.

[4] Y. Zhong, T. Madhujith, N. Mahfouz and F. Shahidi, Compositional characteristics of muscle and visceral oil from steel head trout and their oxidative stability. Food Chemistry, 2007, 104: 602-608.

[5] T. C. Valeria, L. M. Mauricio, A. S. S. Leonor and A. A. P. Luiz, Production and refinement of oil from carp (Cyprinuscarpio) viscera, Food Chemistry, 2010, 119: 945950.

[6] S. Maqsood, S. Benjakul and K. Afaf, Extraction, Processing, and Stabilization of Health-Promoting Fish Oils. Recent
Patents on Food, Nutrition and Agriculture, 2012, 4 (2): 1-7.

[7] M. Shirato, T. Murase, M. Iwata, N. Hayashi, and Y. Ogawa, Studies in screw expression of slurry. Kagaku Kogaku Ronbunshu, 1983, 9 (3): 302-308.

[8] P. C. Bargale, D. Wulfsohn, J. Irudayaraj, R. J. Ford, and F. W. Sosulski, Prediction of oil expression by uniaxial compression using time-varying oilseed properties, Journal of Agricultural Engineering, 2000, 77:171-181.

[9] T. Giuseppe, and F. P. Ester, Evaluation of a mathematical model for oil extraction from oleaginous seeds. Journal of Agricultural Engineering-Riv. diIng. Agr., 2007, 2: 11-20.

[10] S. Pelin, Preliminary design and construction of a prototype canola seed oil extraction machine. Unpublished Master of Science thesis, Department of Mechanical Engineering, Graduate School of Natural and Applied Sciences of Middle East Technical University, 2006, 109 pp.

[11] K. R. Ajao, H. A. Ajimotokan, J. Olaomi and H. Akande, Design and development of a Groundnut oil expelling machine. Journal of Agricultural Technology, 2010, 6 (4): 643-648.

[12] J. A. Adebija, Modification and performance evaluation of a palm kernel seed oil screw press to a castor seed oil screw press, Journal of Agricultural Engineering and Technology (JAET), 2012, 20 (2): 95-106.

[13] J. E. Shigley and C. R. Mischke, Mechanical engineering design, 6th edition, New York: McGraw-Hill Companies, Inc., 2001, Pp 33-105.

[14] R. S. Khurmi and J. K. Gupta, A textbook of machine design, 14th edition, New Delhi: Eurasia Publishing House (PVT) Ltd., 2008, pp 3-500.

[15] M. O. Adesoji, A. Y. Kamaldeen, L. W. Adebayo and O. A. Kunle, Design, Development and Testing of a Screw Press Expeller for Palm Kernel and Soybean Oil Extraction. Unpublished M. Eng. Thesis, Department of Agricultural and Bio-systems Engineering, Faculty of Engineering and Technology, University of Ilorin, Ilorin, Kwara State, Nigeria, 2013, pp 1-9.

[16] A. Fadeyibi, Z. D. Osunde, G. Agidi and E. C. Egwim, Design of single screw extruder for homogenizing bulk solids. Agricultural Engineering International: CIGR Journal,2016, 18(4):222-231.

[17] T. Zehev and and G. G. Costas, Principles of Polymer Processing (2nd Edition). John Wiley and Sons, Inc., Hoboken, New Jersey, 2006, Pp.250-255, 450-474.

[18] A. Fadeyibi, Z. D. Osunde, G. Agidia nd E. C. Egwim, Flow and strength properties of cassava and yam starch-glycerol composites essential in the design of handling equipment for granular solids. Journal of Food Engineering, 2014, 129(15):38-46.

[19] A. S. Hall, A. E. Holowenko and H. G. Laughlin, Schaum's outline series theory and problems of machine design. (1st ed.). New York: McGraw-Hill Companies, Inc., (Chapter 12), 2002.

[20] A. P. Onwualu, C. O. Akubuoand I. E. Ahaneku, Processing of Agricultural Products: Fundamentals of Engineering for Agriculture. Immaculate Publications Limited, Enugu, 2006, pp: 260. 